peripheral non-segmental basilar infiltrates, mass-like consolidation, cavitation and pleural effusion or pleural thickening. ${ }^{2}$

Thoracic actinomycosis is usually the result of aspiration of infected material from the oropharynx. Normal gravitational and anatomical factors result in a predominance of lower-lobe pulmonary disease. ${ }^{3}$ Given the usual aetiology of thoracic actinomycosis, the likely factor in our patient's history was oesophageal perforation many years earlier.

Penicillin is the treatment of choice, in high dose and for a prolonged duration, most usually suggested for several months, but infections could also be polybacterial needing other antibiotics, especially if the recovery is slow. Complications include chronic and progressive sepsis, which may prove fatal. Surgery is reserved as a treatment option where diagnosis is uncertain (suspected neoplasm) or where there is no initial response to antibiotics. 4
To conclude, there should be a high level of suspicion for the presence of actinomyces in cases with draining chest wall sinuses or with spontaneous discharge of an empyema. Recognition of these symptoms might avoid the need for surgery as actinomyces is an extremely penicillin-susceptible organism.

Thorax 2011;66:738-739. doi:10.1136/thoraxjnl-2011-200109

\section{REFERENCES}

1. Mabeza GF, Macfarlane J. Pulmonary actinomycosis. Eur Respir J 2003;21:545-51.

2. Kim TS, Han J, Koh WJ, et al. Thoracic actinomycosis: CT features with histopathologic correlation. AJR Am J Roentenol 2006;186:225-31.

3. Andreani A, Cavazza A, Marchioni A, et al. Bronchopulmonary actinomycosis associated with hiatal hernia. Mayo Clin Proc 2009;84:123-8.

4. Song J, Park HY, Jeon K, et al. Treatment of thoracic actinomycosis: A retrospective analysis of 40 patients. Ann Thorac Med 2010;5:80-5.

\title{
Journal club
}

\section{Scotland's smoking ban means fewer kids in hospital with asthma}

The aim of this study was to determine whether the ban on smoking in public places in Scotland, which was initiated in March 2006, influenced the rate of hospital admission for childhood asthma. The risk of hospital admission was determined from January 2000 to October 2009 among children aged <15 years. Before the ban imposed in March 2006, the number of hospital admissions for asthma was rising by $5.2 \%$ a year among children aged $<15$ years. The public smoking ban reduced the annual rate of serious childhood asthma attacks by $18 \%$ per year. The benefits following the ban were seen in both preschool children and those of school age.

This study shows that there was a reduction in the rate of hospitalisation for childhood asthma after the introduction of legislation to make public places smoke-free, suggesting that the benefits of such legislation can extend to populations other than those with occupational exposure to environmental tobacco smoke.

Mackay D. Haw S, Ayres J, et al. Smoke-free legislation and hospitalization for childhood. N Engl J Med 2010;363:1139-45.

\section{Atul Gupta}

Correspondence to Atul Gupta, Senior Research Fellow, Royal Brompton Hospital and NHLI Imperial College, Sydney Street, London SW3 6NP, UK; atulgupta@doctors.org.uk

Published Online First 29 October 2010

Thorax 2011;66:739. doi:10.1136/thx.2010.153510 